\title{
A Potential Bioactive Secondary Metabolites and Antimicrobial Efficacy of Streptomyces thermocarboxydus Strain KSA-2, Isolated from Kali River, Karwar
}

\section{Sreenivasa Nayaka*a, Muthuraj R. ${ }^{b}$, Bidhayak Chakraborty ${ }^{b}$, Meghashyama Prabhakara Bhat ${ }^{b}$, Pallavi S.S. ${ }^{b}$ Shashiraj K.N. b, Halaswamy H.M. ${ }^{\text {, }}$, Dhanyakumara S.B. b, Dattatraya Airodagi. b, Kavitha Hagedc.}

a Assistant Professor, Dept. of P.G. studies in Botany, Karnatak University Dharwad, Karnataka, India.

${ }^{b}$ Research scholar Dept. of P.G. studies in Botany, Karnatak University, Dharwad, Karnataka, India.

c M.Sc. Dept. of P.G. studies in Botany, Karnatak University, Dharwad, Karnataka, India.

E-mail: a sreenivasanayaka06@gmail.com

Received: 30th Mar2020 Revised: 27h May $2020 \quad$ Accepted: 8 $^{\text {th }}$ sept $2020 \quad$ DOI: https://doi.org/10.31559/CRMI2020.1.1.2

Abstract: In the present study, an Actinomycetes strain KSA-2 was isolated from freshwater sediment samples of Kali River, Karwar, Karnataka, India. The strain KSA-2 was selected among seven isolates based on primary screening of antimicrobial activity against pathogenic organisms. The morphological physiological and biochemical characterizations were performed, the bioactive secondary metabolites were produced in liquid broth culture and was characterized by UV-Vis. spectroscopy and FTIR spectroscopy. Later, the potent KSA-2 strain was identified by $16 \mathrm{~S}$ rRNA gene sequencing (1366 bp) and a phylogenetic tree was constructed and the strain KSA-2 was confirmed as Streptomyces thermocarboxydus strain KSA-2. Further, the characterization of methanolic extract by UV-Vis. and FTIR spectroscopy analysis revealed the presence of broad spectrum of antimicrobial and other compounds and alkyl halides, alkenes, sulfoxide, carboxylic acids, alkanes respectively.

Keywords: Streptomyces thermocarboxydus; antimicrobial activity; FTIR; 16S rRNA gene sequencing; phylogenetic tree.

${ }^{*}$ Corresponding author

Sreenivasa Nayaka

Assistant Professor, Dept. of P.G. studies in Botany, Karnatak University Dharwad, Karnataka, India.

E-mail: sreenivasanayaka06@gmail.com 


\section{Introduction}

Actinomycetes are the group of bacteria belongs to the family Actinomycetaceae, they are grampositive, filamentous, branching, and prokaryotic bacteria with high Guanine (G) and Cytosine (C) content (above 55\%) in their DNA (Sheik et al. 2017). These organisms are one of the most industrially, biotechnologically and economically important prokaryotes for production of 70 to $80 \%$ of existing secondary metabolites (Rao and Navabharath 2016). Surprisingly, they have the characteristic features of both bacteria and fungi and hence, they are kept in a special class named Actinobacteria. The members of the genus Actinomycetes are omnipresent, however most of them are found in soil, freshwater, and marine ecosystems (Daniel et al. 2014). Soil is considered as a good source for isolation and characterization of potent microorganisms for the production of antibiotics, in which the actinomycetes are wellknown microorganisms for their antibiotic production (Nayaka et al. 2018). There are many research works reported worldwide on freshwater actinomycetes, but in India the research on freshwater actinomycetes is in pioneer stage and less explored compared to marine and terrestrial actinomycetes (Zothanpuia et al. 2015). The exclusive capacities of these strains to produce many potent bioactive metabolites are commercially valuable. Bioactive compounds from actinomycetes endowed with biological activities with chemical skeleton (Mangamuri et al. 2016). They are major sources for the production of bioactive secondary metabolites which are commercially important, natural occurrences of actinomycetes because of their capacity to produce many enzymes, secondary metabolites, hormones, vitamins, pigments, and antibiotics by utilizing environmental factors.

In a recent study, it was found that there are 12,000 identified antibiotics, in which $70 \%$ of the antibiotics were produced by actinomycetes only (Nasri et al. 2017). Actinomycetes are more useful in the field of pharmaceutical industries because of their unlimited capacity to produce secondary metabolites, enzymes, antibiotics, antimicrobial metabolites notably aminoglycosides, macrolides, polyenes, glycopeptides, polyketides, beta-lactides, actinomycins (Daniel et al. 2014). Screening of actinomycetes in artificial media under laboratory conditions for the synthesis of secondary metabolites is remarkable work in the field of pharmaceutical industries because the different species of same genera are capable to produce different secondary metabolites, enzymes, antibiotics. In the secondary metabolite biosynthesis pathway with a gene cluster of the actinomycetes is ranging from 20 to 50 per genome, so the actinomycetes are invaluable prokaryotes used in genome mining. The members of the genus Streptomyces are the only genus, which can produce more than $60 \%$ of the total antibiotics worldwide (Baniya et al. 2018). Therefore, keeping these points in mind; a Streptomyces strain was isolated from fresh water sediments samples of the Kali River, which was further analysed through 16S rRNA gene sequencing. The bioactive compound produced by this organism was characterized by UV-Vis. and FTIR spectrophotometer.

\section{Materials and Methods}

\section{Sampling area and sample collection}

The samples were collected from the sediments of the Kali River, Karwar, Karnataka, India. The river is located at latitude: $14^{\circ} 50^{\prime} 19.19^{\prime \prime} \mathrm{N}$ and longitude: $74^{\circ} 07^{\prime} 13.80^{\prime \prime} \mathrm{E}$ and it flows to the Arabian Sea. A total of 10 sediment samples were collected from 2 $m$ depth of the river using a sediment sampler and later transferred to wide-mouthed sterilized bottles. At the same time the samples in the bottles were labeled and transported to the microbiology laboratory, P.G. Department of studies in Botany, Karnatak University, Dharwad and stored at $4{ }^{\circ} \mathrm{C}$ for future work.

\section{Isolation of actinomycetes}

Collected samples were subjected to physical and chemical pre-treatment methods to facilitate the precise isolation of actinomycetes. $1 \mathrm{~g}$ of sediment sample was dissolved in $9 \mathrm{ml}$ sterilized distilled water and vortexed for $2 \mathrm{~min}$, which was later subjected to heat treatment in a hot water bath at 60 ${ }^{\circ} \mathrm{C}$ for $10 \mathrm{~min}$ to remove the population of nonsporulating bacteria. The isolation of actinomycetes was performed on starch casein agar (SCA) medium supplemented with Amphoterecin-B and Tetracycline $(50 \mu \mathrm{l} / \mathrm{ml}$ each) to inhibit the growth of unwanted fungal and bacterial organisms. Slurry was prepared by vortexing $1 \mathrm{~g}$ of sediment sample in $9 \mathrm{ml}$ of sterile distilled water and a 10 -fold serial dilution was made. Later, $0.1 \mathrm{ml}$ of diluted sample from each tube was transferred and spread onto SCA medium under aseptic conditions. The plates were incubated at $33{ }^{\circ} \mathrm{C}$ for 7 days with periodic observation on growth. At last, the isolated colonies of actinomycetes were picked up, purified and maintained in starch casein medium slants at $4{ }^{\circ} \mathrm{C}$ (Kugbere 2014).

\section{Primary screening of isolated actinomycetes}

The isolated actinomycetes were screened for antimicrobial activity by cross streak method against selected pathogenic fungus and bacteria, such as Aspergillus fumigatus (MTCC8877), Enterobacter aerogenes (ATCC2822) Staphylococcus epidermidis (MTCC435) and Shigella flexneri (MTCC1457). For primary screening; the isolated actinomycetes were streaked at the centre of the plates as straight lines on nutrient agar (NA) medium followed by incubation at $33{ }^{\circ} \mathrm{C}$ for 5 to 7 days. After incubation period; the $24 \mathrm{~h}$ freshly cultured fungus and bacteria were streaked 90 
degree perpendicular to the growth of actinomycetes isolates and incubated for $24 \mathrm{~h}$ at 37 ${ }^{\circ} \mathrm{C}$ according to Balachandar et al. (2018). The zone of inhibition was observed and recorded. The most powerful and effective actinomycetes was taken for further characterizations.

\section{Morphological, physiological and biochemical characterizations}

The morphological characterization of the potential strain KSA-2 was done by Gram's staining and cover slip insertion culture method on SCA medium. Physiological characterizations were done by growing the strain KSA-2 at verifying range of $\mathrm{pH}$ from $\mathrm{pH} 6$ to $\mathrm{pH} 8$ and temperature range from $20^{\circ} \mathrm{C}$ to $60{ }^{\circ} \mathrm{C}$. The growth at different $\mathrm{NaCl}$ concentration starting from $1 \%$ to $7 \%$ of the isolated strain was also noted. Biochemical characterization was done by hydrolysis of starch, casein, urea, and gelatin. The starch hydrolysis was done by inoculating the strain KSA-2 on starch agar medium and incubating for 7 days, followed by flooding the medium with $1 \%$ iodine solution. A clear hydrolytic zone around the colony symbolized the hydrolysis of starch. For hydrolysis of casein; the isolated KSA-2 organism was inoculated on Skimmed milk agar medium and incubated up to 7 days at $33{ }^{\circ} \mathrm{C}$. The clear zones around the colony indicated the hydrolysis of casein, in the same way the utilization of urea was checked by using Christensen's urea agar medium, the color change from yellow to pink indicated the utilization of urea. The gelatin utilization was done by inoculating organisms on actinomycetes isolation agar (AIA) medium containing 1\% gelatin followed by incubation at $33^{\circ} \mathrm{C}$ for 3 to 5 days. The formation of the zone around the colonies after flooding by $15 \%$ mercuric chloride solution indicated gelatin hydrolysis. Hydrogen sulfide $\left(\mathrm{H}_{2} \mathrm{~S}\right)$ production and nitrate reduction was tested in sulphite indole motility (SIM) medium and nitrate broth respectively. The potentiality of the isolated organisms for the utilization of carbon sources like D-Glucose, arabinose, cellulose, trehalose, Dfructose, mannitol, sucrose, xylose, raffinose, and mannose were tested by streaking the organism on carbohydrate utilization medium. Bromocresol purple was added to the basal medium and the $\mathrm{pH}$ was adjusted to $7.0 .1 \%$ of different sterile carbohydrate solutions were added to the respective sterile medium. The strain KSA-2 was inoculated in all media and incubated at $33^{\circ} \mathrm{C}$ for 5 to 7 days. One slant was kept as control without addition of carbohydrate solution (Maria et al. 2018).

\section{Molecular identification of the strain KSA-2}

The genomic DNA was extracted from fresh culture potent strain KSA-2. The 16S rRNA genes were amplified using two universal primers, namely forward primer and reverse primer. The thermal conditions maintained for PCR amplification were at $96^{\circ} \mathrm{C}$ for $5 \mathrm{~min}$ for initial denaturation of 25 cycles, denaturation at $96^{\circ} \mathrm{C}$ for $1 \mathrm{~min}$, hybridization at 50 ${ }^{\circ} \mathrm{C}$ for $1 \mathrm{~min}$, and elongation at $60^{\circ} \mathrm{C}$ for $2 \mathrm{~min}$. The amplified PCR products were electrophoresed on $1 \%$ agarose gel with 500 base pairs of DNA ladder as a size reference. The purified amplicons were sequenced using an automated DNA sequence instrument and used to interrogate in the NCBI database via BLASTN web portal. The top 10 DNA sequences based on highest score of phylogenetic neighbours obtained from BLASTN analysis were aligned using CLUSTAL-X software. Further, a phylogenetic tree was constructed by neighbour joining method using MEGA 7.0 software (Salim et al. 2017).

\section{Fermentation and extraction of bioactive compound}

The isolated potent actinomycetes strain KSA-2 was grown in starch casein broth (pH 7.0) and incubated at $33{ }^{\circ} \mathrm{C}$ in a rotator shaker $(150 \mathrm{rpm})$ for 14 days. After the incubation period; the KSA-2 biomass was separated by centrifugation at 5000 rpm for 20 min and washed with sterilized distilled water 3 times. In order to collect the intra-cellular bioactive compounds, the biomass of the strain KSA2 was suspended in a small amount of methanol in the ratio of $1: 1(\mathrm{w} / \mathrm{v})$ and ground with a pestle and mortar. Later, the mixture was shaken vigorously overnight followed by filtration through Whatman No.1 filter paper. The filtrate was evaporated using rotatory shaker at $50{ }^{\circ} \mathrm{C}$ and the concentrated extract was transferred to glass screw-cap tubes and stored at $4^{\circ} \mathrm{C}$ for further use (Mangamuri et al. 2016).

\section{Characterizations of intra-cellular bioactive compounds}

The intra-cellular methanol extract of strain KSA2 was subjected to UV-Vis. spectroscopic analysis using Jasco V-670 UV/ViS spectrophotometer for possible determination of natural compounds. The bioactive functional groups present in the methanol extract were ascertained by FTIR spectroscopy. For FTIR analysis; a pinch of extract was mixed with $\mathrm{KBr}$ using a mortar and pestle, which was compressed to make small thin discs. Later, these discs were analyzed in the range of 400 to $4000 \mathrm{~cm}^{-1}$ using a Nicolet 6700 FTIR spectrometer (Vineeta et al. 2016).

\section{Results and Discussion}

\section{Isolation and morphological characterization of} actinomycetes

The clear and distinguishable 17 colonies of actinomycetes isolates were isolated on SCA medium from 6 samples collected from fresh water sediments of Kali River, Karwar. The colonies showed different color of substrate and aerial mycelia. There are many studies reported the isolation of actinomycetes from various samples like soil (Nayaka et al. 2018), water and sediments 
(Gebreyohannes et al. 2013), endophtyes (Taechowisan et al. 2005). Among these less work on unexplored fresh water actinomycetes compared to marine and soil actinomycetes for secondary metabolites. The isolated organisms were screened for selection of potent strain of actinomycetes.

\section{Primary screening:}

17 actinomycetes isolates from the sediment's samples were screened against 4 pathogenic organisms, such as Aspergillus fumigatus, Enterobacter aerogenes, Staphylococcus epidermidis, and Shigella flexneri. The isolated actinomycetes showed a broad-spectrum antimicrobial activity against the tested microorganisms in the perpendicular streak method, but the strain KSA-2 (Fig. 1) showed most powerful antimicrobial activity against all the four selected pathogens (Fig. 2 and Table 1). This was due to some sort of strong antibiotic substances produced by the actinomycetes, which were later diffused in the medium and inhibited the growth of pathogens. This result was compared with the similar results of Gebreyohannes et al. (2013), where among 31 isolated actinomycetes from water and sediments samples of river; 11 isolates showed good zone of inhibition on cross streak method. The discovery of novel antibiotics from unexplored water reservoir for multidrug resistant pathogenic organisms gain the importance in the field of pharmaceuticals because the treatment to the multidrug resistant pathogens creating challenging problems (Duddu et al. 2016). In search of new antibiotics; one of the very rapid and easy methods for screening cultures was cross streak or perpendicular streak method, because cross streak method shows higher inhibition zone than agar well diffusion method (Velho et al. 2011).
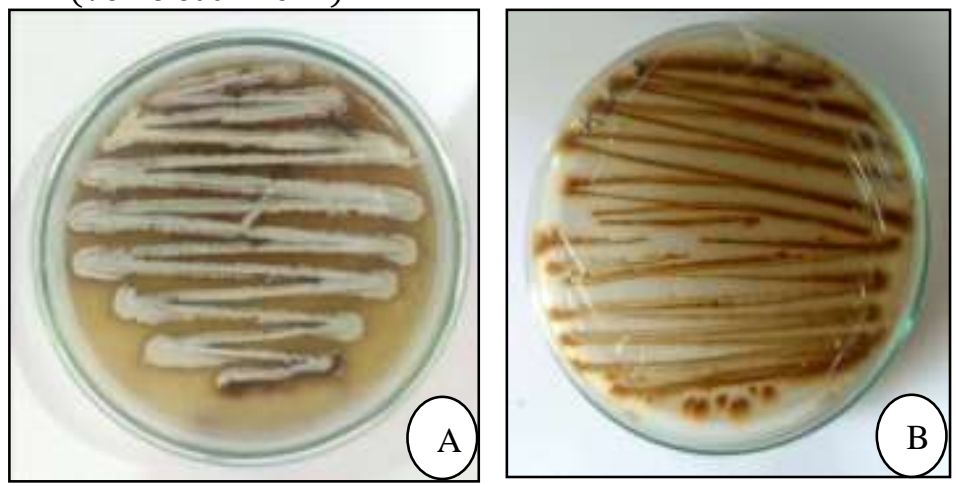

Fig (1): Morphological features of Streptomyces thermocarboxydus strain KSA-2. (A) Aerial mycelium and (B) Substrate mycelium.
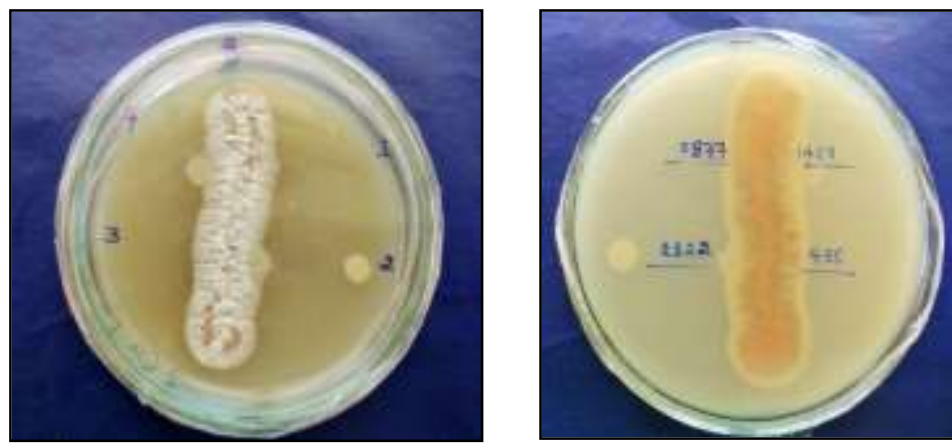

Fig (2): Cross Streak-plating technique to screen the antibacterial activity of isolated Streptomyces thermocarboxydus strain KSA-2. Aspergillus fumigatus (8877), Enterobacter aerogenes (2822), Staphylococcus epidermidis (435), Shigella flexneri (1457).

Table (1): Primary screening of active isolates of actinomycetes using cross-streak method against pathogenic bacteria

\begin{tabular}{|c|c|c|c|c|}
\hline Stain No. & $\begin{array}{l}\text { A. fumigatus } \\
\text { (MTCC8877) }\end{array}$ & $\begin{array}{l}\text { E. aerogenes } \\
\text { (ATCC2822) }\end{array}$ & $\begin{array}{l}\text { S. epidermidis } \\
\text { (MTCC435) }\end{array}$ & $\begin{array}{r}\text { S. flexneri } \\
\text { (MTCC1457) }\end{array}$ \\
\hline KSA-1 & & ++ & - & + \\
\hline KSA-2 & +++ & ++ & +++ & +++ \\
\hline KSA-3 & - & ++ & + & - \\
\hline KSA-4 & + & - & - & + \\
\hline KSA-5 & ++ & + & - & + \\
\hline KSA-6 & - & - & + & ++ \\
\hline KSA-7 & - & ++ & - & + \\
\hline KSA-8 & + & ++ & - & - \\
\hline KSA-9 & +++ & - & ++ & - \\
\hline KSA-10 & - & + & + & + \\
\hline KSA-11 & - & + & - & + \\
\hline KSA-12 & ++ & - & - & ++ \\
\hline KSA-13 & - & - & + & + \\
\hline KSA-14 & +++ & - & - & + \\
\hline KSA-15 & - & - & + & - \\
\hline KSA-16 & + & + & + & - \\
\hline KSA-17 & + & - & ++ & + \\
\hline
\end{tabular}

- No growth; +: Normal growth; ++: Moderate growth; +++: Optimum growth

\section{Morphological, physiological and biochemical characterizations}

The morphological, physiological and biochemical characterizations of the strain KSA-2 were shown in Table 2. The morphological characterization of the strain KSA-2 revealed grey or beige colored aerial mycelium, whereas the substrate mycelium was light brown in color. However, the organism also produced a light brown diffusible pigment. The optimum $\mathrm{pH}$ favorable for the growth of KSA-2 was found in the range of $\mathrm{pH}$ 7.0, but moderate growth was recorded at $\mathrm{pH} 6.5$ and $\mathrm{pH}$ 7.5. The strain KSA-2 was found to grow best at $45{ }^{\circ} \mathrm{C}$ temperature, hence it was considered as moderately thermophilic organism, the average 
growth was observed at $40{ }^{\circ} \mathrm{C}$ and $50{ }^{\circ} \mathrm{C}$. Interestingly, the organism was even found to grow best at $3 \% \mathrm{NaCl}$ concentration, which implies the organism grows best at moderately halophilic ecosystem. The organism KSA-2 was found positive for gram staining and spore staining. During biochemical characterization, the isolated strain KSA-2 revealed positive result for the hydrolysis of starch, casein and gelatin. Urea however was not utilized by the organism KSA-2. The hydrolysis of starch, casein and gelatin revealed the organism's ability to produce amylase, protease and gelatinase enzymes respectively. The organism even showed positive result for nitrate reduction by the activity of enzyme nitrate reductase.
The formation of red color in broth confirmed nitrate reduction.

The carbon sources utilized by the strain KSA-2 were D-Glucose, arabinose, trehalose, D-fructose, mannitol and no utilization observed in sucrose, cellulose, raffinose, and xylose. Hydrogen sulfide production by the strain KSA-2 confirmed by change in the color of the SIM medium from light yellow to black, which meant the strain KSA-2 produced hydrogen sulfide $\left(\mathrm{H}_{2} \mathrm{~S}\right)$ gas in the presence of sulphur compounds. The iron compounds present in the medium reacted with hydrogen sulfide gas and thereby formed a black precipitate. The result obtained by us can be compared with the result of Pathalam et al. (2017).

Table (2): Morphological, physiological and biochemical characteristics of the Streptomyces thermocarboxydus strain KSA-2

\begin{tabular}{|c|c|}
\hline Characteristics & Strain KSA-2 \\
\hline Colour of aerial mycelium & Grey beige \\
\hline Colour of substrate mycelium & Light brown \\
\hline Pigmentation & Light brown \\
\hline \multicolumn{2}{|c|}{ Growth at $\mathrm{pH}$} \\
\hline pH6.0 & - \\
\hline pH6.5 & + \\
\hline pH7.0 & ++ \\
\hline pH7.5 & + \\
\hline pH8.0 & - \\
\hline \multicolumn{2}{|c|}{ Growth at Temperature } \\
\hline $20^{\circ} \mathrm{C}$ & - \\
\hline $25^{\circ} \mathrm{C}$ & + \\
\hline $30^{\circ} \mathrm{C}$ & + \\
\hline $35^{\circ} \mathrm{C}$ & + \\
\hline $40^{\circ} \mathrm{C}$ & ++ \\
\hline $45^{\circ} \mathrm{C}$ & +++ \\
\hline $50^{\circ} \mathrm{C}$ & ++ \\
\hline $55^{\circ} \mathrm{C}$ & + \\
\hline $60^{\circ} \mathrm{C}$ & - \\
\hline $\mathrm{NaCl}$ tolerance & $3 \%$ \\
\hline Gram staining & + \\
\hline Spore staining & + \\
\hline Nitrate reduction & + \\
\hline $\mathrm{H}_{2} \mathrm{~S}$ production & + \\
\hline \multicolumn{2}{|c|}{ Hydrolysis } \\
\hline Starch & + \\
\hline Casein & + \\
\hline Urea & - \\
\hline Gelatin & + \\
\hline \multicolumn{2}{|c|}{ Carbon source utilization } \\
\hline D-Glucose & + \\
\hline Sucrose & - \\
\hline Arabinose & + \\
\hline Raffinose & - \\
\hline Cellulose & - \\
\hline Trehalose & + \\
\hline D-fructose & + \\
\hline Mannitol & + \\
\hline Xylose & - \\
\hline
\end{tabular}

- No growth; +: Normal growth; ++: Moderate growth; +++: Optimum growth 


\section{S rRNA gene sequencing}

The genomic DNA from the strain KSA-2 was analyzed by $16 \mathrm{~S}$ rRNA gene sequencing by the PCR amplification. The 16S rRNA is the segment of RNA which is present in the $30 \mathrm{~S}$ subunit of ribosome of the strain, which is useful in identification of microorganisms up to species level. The 16S rRNA gene sequence obtained was 1366 base pairs in length. The sequence however was submitted to the NCBI genebank along with the accession number MK905526, and the close relative microorganisms were searched through Nucleotide BLAST (BLASTN) in NCBI. The BLAST result of $16 \mathrm{~S}$ rRNA sequence of strain KSA-2 revealed that $99.56 \%$ sequence similarity with Streptomyces thermocarboxydus strain EGI124 (MN704433) and Streptomyces thermocarboxydus strain A15 (MK680818). Later, the phylogenetic tree was constructed using MEGA 7.0 software through neighbor-joining method from obtained gene sequences, the phylogenetic tree analysis revealed that Streptomyces thermocarboxydus strain KSA-2 forms within the cluster of the genus Streptomyces and forms branch with Streptomyces sp. FZ46 (KF803314) (Fig. 3). These results were correlated with the results of Priyanka (2019).

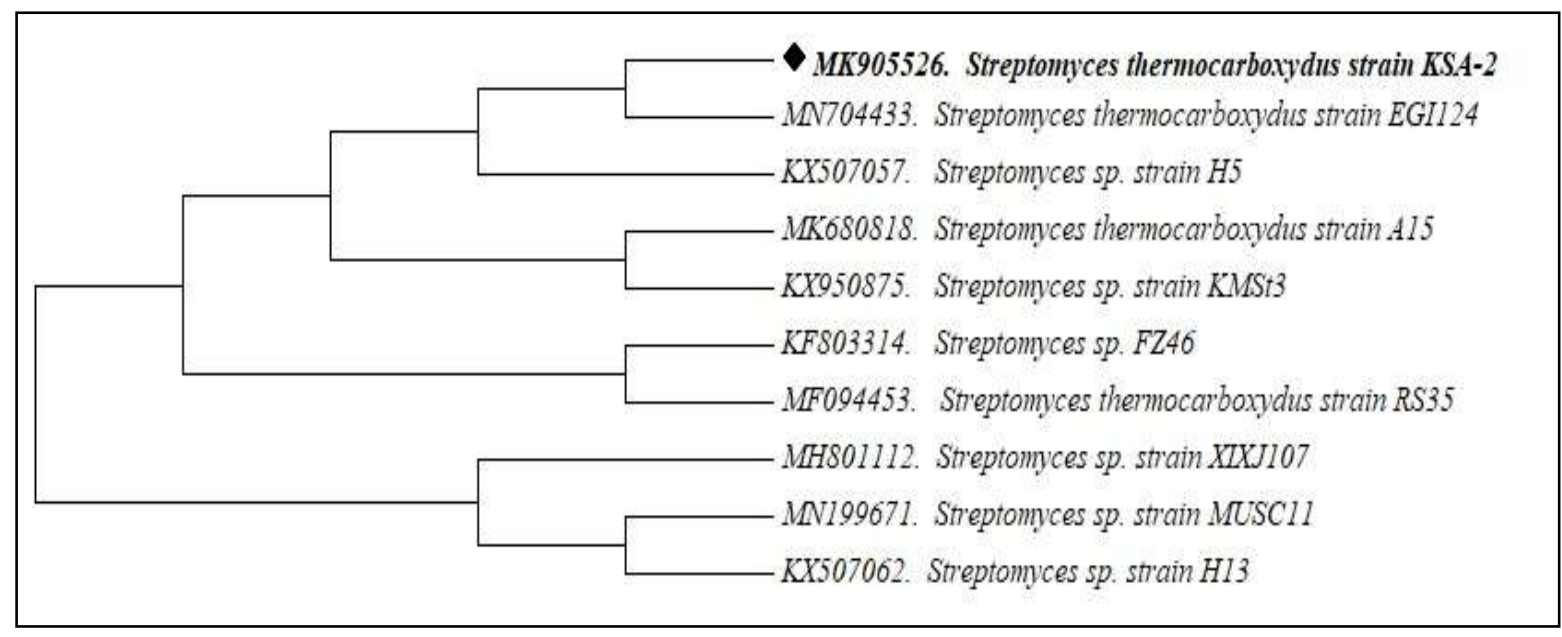

Fig (3): Dendrogram showing phylogenetic relation of Streptomyces thermocarboxydus strain KSA-2

\section{UV-Vis Analysis of KSA-2 methanol extract}

The UV-visible spectroscopy was used for quantitative analysis of metabolites, it showed absorption peak of chromatic solutions. The aromatic solutions have high chromophores in UV range. The methanol extracts of KSA-2 exhibited the UV absorption peak from 200nm to $700 \mathrm{~nm}$ (Fig. 4). It was used for qualitative analysis of the bioactive compound and showed maximum absorption peak at $260 \mathrm{~nm}$ in methanol. The characteristics of absorption peak indicated a high polyene nature.

The absorbance peak was formed because establishment of disulfide bond between two cysteine residues. Therefore, it was presumed the KSA-2 produced a broad spectrum of anti-microbial or other compounds with different activities.

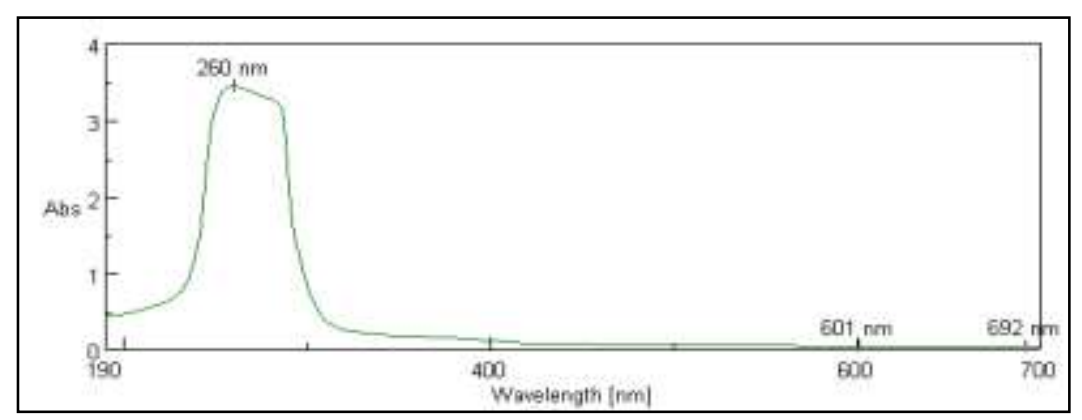

Fig (4): UV-Spectrum of Streptomyces thermocarboxydus strain KSA-2 methanol extract

\section{FTIR analysis of methanol extract of KSA-2}

The uses of FTIR spectroscopy are widespread because of its ability to conduct large screening experiments and functional group analysis of metabolites of biological samples, which gives results very quickly and accurately. The bio- molecular compounds present in methanol extracts of KSA-2 were determined by virtue of peak values of FTIR bands obtained at 538, 618, 929, 1048, 1082, $1113,1353,1047,1462,1586,1631,2853,2924$, 2960, $3421 \mathrm{~cm}^{-1}$ (Fig. 5 and Table 3). The peak values unveiled the presence of alkyl halides at 538 
$\mathrm{cm}^{-1}$ and $618 \mathrm{~cm}^{-1}$, alkenes at $929 \mathrm{~cm}^{-1}$ and $1631 \mathrm{~cm}^{-}$ 1 , sulfoxide at $1048 \mathrm{~cm}^{-1}$, primary and secondary alcohol at $1082 \mathrm{~cm}^{-1}$ and $1113 \mathrm{~cm}^{-1}$ respectively, sulfonamides at $1353 \mathrm{~cm}^{-1}$, sulfonyl chloride at 1407 $\mathrm{cm}^{-1}$, carboxylic acids at $1405 \mathrm{~cm}^{-1}$, alkanes at 1462 $\mathrm{cm}^{-1}, 2853 \mathrm{~cm}^{-1}, 2924 \mathrm{~cm}^{-1}$ and $2960 \mathrm{~cm}^{-1}$, primary amines at $1586 \mathrm{~cm}^{-1}$ and $3421 \mathrm{~cm}^{-1}$. The FTIR analysis confirmed the functional groups produced from KSA-2 strain were alkenes, alkanes, alchohols, amines, alkyl halides, and sulfonyl groups.
The presence of different intracellular components in KSA-2 strain produced different secondary metabolites. It was reported that the alcoholic group of metabolites at $1082 \mathrm{~cm}^{-1}$ and $1113 \mathrm{~cm}^{-1}$ shows inhibition against pathogenic organisms Kuley et al (2017). Because of the potency of the KSA-2 strain to produce various bioactive compounds; it showed good antimicrobial activity against selected pathogens and the results were compared with similar results of Nayaka et al (2019).

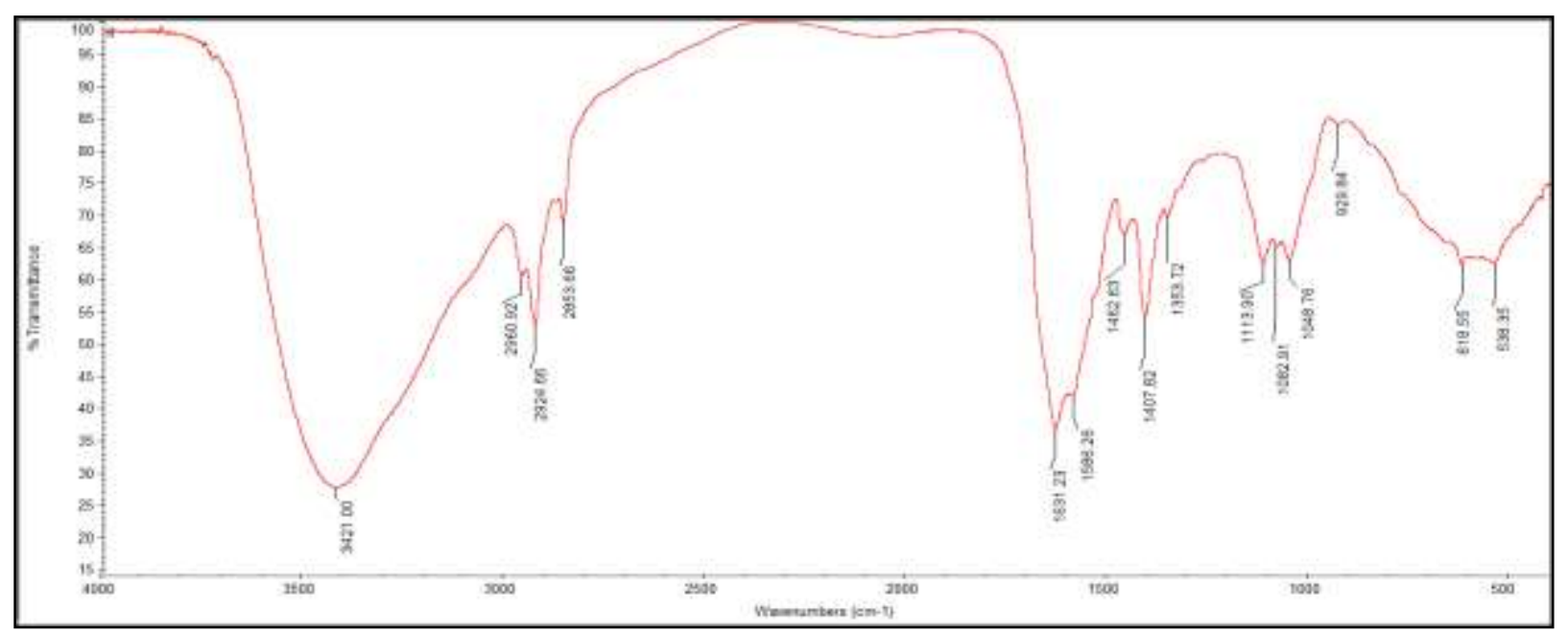

Fig (5): FTIR Spectrum of Streptomyces thermocarboxydus strain KSA-2 methanol extract

Table (3): FTIR absorption peak and their associated functional groups of Strepyomyces thermocarboxydus strain KSA-2 methanol extract

\begin{tabular}{|c|c|c|}
\hline Sl. No. & Absorption peak $\left(\mathrm{cm}^{-1}\right)$ & Functional groups \\
\hline 1 & 538 & C-Br Stretching Alkyl halides \\
\hline 2 & 618 & C-Br Stretching Alkyl halides \\
\hline 3 & 929 & $\mathrm{C}=\mathrm{C}$ Bending alkenes \\
\hline 4 & 1048 & $S=0$ Stretching sulfoxide \\
\hline 5 & 1082 & $\begin{array}{c}\text { C-O stretching Primary } \\
\text { alcohol }\end{array}$ \\
\hline 6 & 1113 & $\begin{array}{l}\text { C-O stretching Secondary } \\
\text { alcohol }\end{array}$ \\
\hline 7 & 1353 & $\mathrm{~S}=0$ Stretching sulfonamide \\
\hline 8 & 1407 & $\begin{array}{c}\mathrm{S}=0 \text { Stretching Sulfonyl } \\
\text { chloride }\end{array}$ \\
\hline 9 & 1462 & C-H Bending Alkane \\
\hline 10 & 1586 & $\mathrm{~N}-\mathrm{H}$ Bending amines \\
\hline 11 & 1631 & $\mathrm{C}=\mathrm{C}$ stretching alkenes \\
\hline 12 & 2853 & C-H Stretching alkanes \\
\hline 13 & 2924 & C-H Stretching alkanes \\
\hline 14 & 2960 & C-H Stretching alkanes \\
\hline 15 & 3421 & $\begin{array}{c}\mathrm{N}=\mathrm{H} \text { Stretching primary } \\
\text { amines }\end{array}$ \\
\hline
\end{tabular}

\section{Conclusion}

The present study was focused on functional screening of potent fresh water sediment actinomycetes against four pathogenic microorganisms, among the isolates the Streptomyces thermocarboxydus strain KSA-2 showed good activity and it was selected for production of bioactive secondary metabolites. The partial characterization of bioactive secondary metabolites by FTIR and UV-Vis. spectrophotometer revealed the presence of different bioactive compounds produced by KSA-2 strain. The separation and purification of bioactive compounds produced from actinomycetes are being encouraged recently in pharmaceutical industries due to the presence of some novel secondary metabolites having antitumor, antiviral, enzyme inhibitor and other bioactive properties. In further investigation, the work on Streptomyces thermocarboxydus strain 
KSA-2 can be undertaken to identify and structure elucidation of potential bioactive compounds.

Acknowledgement: The authors are thankful to the UGC-SAP-DSA-I, Department of Botany, Karnatak University, Dharwad, Karnataka, India, for laboratory facilities. The authors are also thankful to the University Scientific and Instrumentation Centre, Karnatak University, Dharwad for necessary instrument facilities.

Conflict of Interests: The authors declare that there is no conflict of interests between them.

\section{References}

[1] Balachandar. R., Karmegam. N., Saravanan. M., Subbaiya. R., Gurumoorthy. P. (2018). Synthesis of bioactive compounds from vermicast isolated actinomycetes species and its antimicrobial activity against human pathogenic bacteria, Microb Pathog, 121: 155-65, doi: 10.1016/j.micpath.2018.05.027.

[2] Baniya. A., Singh. S., Singh. M., Nepal. P., Adhikari. M., Aryal. S., Adhikari. A. (2019). Isolation and Screening of Antibiotics Producing Streptomyces spp from the Soil Collected around the Root of Alnus nepalensis from Godawari, Nepal J Biotechnol, 6(1): 46-56, doi:10.3126/njb.v6i1.22337.

[3] Daniel. K., Guravaiah. M., Lakshmi. RK., Revathi. T., Rani. UK., Nirosha. P., Kumar. SS. (2014). Screening, isolation and production of bioactive compounds from marine actinomycetes, Int J Inn Res Sci Eng Technol, 3(3):10827-838, doi:10.15680/IJIRSET.2014.0303120.

[4] Duddu. MK., Guntuku. GG. (2016). Isolation, screening and characterization of antibiotic producing actinomycetes from kapuluppada plastic waste dumping yard, visakhapatnam. Int j pharm pharm sci, 8(11): 221-229,

doi: https://doi.org/10.22159/ijpps.2016v8i11.10110.

[5] Gebreyohannes. G., Moges. F., Sahile. S., Raja. N. (2013). Isolation and characterization of potential antibiotic-producing actinomycetes from water sediments of lake Tana Ethiopia, Asian Pac J Trop Biomed, 3(6): 426-435, doi: 10.1016/S2221-1691(13)60092-1.

[6] Kugbere. SA. (2014). Isolation of Actinomycetes from Soil, J Microbiol Res, 4(3): 136-140. doi: 10.7324/JAPS.2017.70909.

[7] Kuley. E., Durmus. M., Balikci. E., Ucar. Y., Regenstein. JM., Ozogul. F. (2017). Fish spoilage bacterial growth and their biogenic amine accumulation: Inhibitory effects of olive byproducts, Int.J. Food. Prop, 20(5): 1029-1043, doi.org/10.1080/10942912.2016.1193516.

[8] Mangamuri. U., Muvva. V., Poda. S., Naragani. K., Munaganti. RK., Chitturi. B., Yenamandra. V. (2016). Bioactive metabolites produced by Streptomyces Cheonanensis VUK-A from Coringa mangrove sediments: isolation, structure elucidation and bioactivity, 3 Biotech, 6(1), 63, doi:10.1007/s13205-016-0398-6.

[9] Maria. ABF., Sharmili. AS., Anbumalarmathi. J. (2018). Isolation and characterization of actinomycetes from marine soil, MOJ Biol Med, 3(6), 221-25, doi: 10.15406/mojbm.2018.03.00103
[10] Nasri. MR., Baserisalehi. M., Kurdtabar. M. (2017). Isolation and identification of halophilic actinomyces with antimicrobial activity and partial characterization of their bioactive compounds, Electron J Biol, 13(4): 383-90.

[11] Nayaka. S., Chakraborty. B., Swamy. PS, Bhat. MP, Airodagi. D., Basavarajappa. DS, Rudrappa. M., Hiremath. H., Nagaraja. SK, Madhappa. C. (2019). Isolation, characterization, and functional groups analysis of Pseudoxanthomonas indica RSA-23 from rhizosphere soil, J Appl Pharm Sci, 9(11): 10106, doi: 10.7324/JAPS.2019.91113.

[12] Nayaka. S., Chethan. JD., Babu. GK., Hospet. R., Pallavi SS., Chakraborty. B. (2018). Molecular characterization and antimicrobial efficacy of Streptomyces gancidicus Strain SN-3 from Soil Samples, J Microbiol Res, 8(4): 97-02, doi: 10.5923/j.microbiology.20180804.02.

[13] Pathalam. G., Rajendran. HAD., Appadura. DR., Gandhi. MR., Michael GP., Savarimuthu. I., Naif. AAD. (2017). Isolation and molecular characterization of actinomycetes with antimicrobial and mosquito larvicidal properties, Beni-Suef Univ J Basic Appl Sci, 6(2): 209-17, doi: 10.1016/j.bjbas.2017.04.002

[14] Pradhan. S., Mishra. BB., Rout. S. (2015). Screening of novel actinomycetes from near Lake shore sediment of the Chilika Lake Odisha India, Int J Curr Microbiol Appl Sci, 4(8): 66-82.

[15] Priyanka. SB. (2019). Isolation, purification, and characterization of pectinase enzyme from Streptomyces thermocarboxydus, I Clinical Microbiol Biochem Technol, 1(5): 1-6, doi.org/10.17352/jcmbt.000031.

[16] Rahman. MA., Islam. MZ., Islam. MAU. (2011). Antibacterial Activities of Actinomycete Isolates Collected from Soils of Rajshahi, Bangladesh, Biotechnol Res Int, 201116, doi:10.4061/2011/857925.

[17] Rao. S., Navabharath. (2016). Studies on antibiotic producing potential of actinomycetes isolated from dump yard soil and sediments from fresh water reservoir, World J Pharm Med Res, 2(6): 156-62.

[18] Salim. FM., Sharmili. SA., Anbumalarmathi. J., Umamaheswari. K. (2017). Isolation molecular characterization and identification of antibiotic producing actinomycetes from soil samples, $J$ Appl Pharm Sci, 7(9): 69-75, doi: 10.7324/JAPS.2017.70909.

[19] Sheik. GB., Maqbul. MS., Shankar. GS., Ranjith. MS. (2017). Isolation and characterization of actinomycetes from soil of Ad-Dawadmi, Saudi Arabia and Screening their antibacterial activities, Int J Pharm Pharm Sci, 9(10): 27679, doi.org/10.22159/ijpps.2017v9i10.15402.

[20] Taechowisan. T., Lu. C., Shen. Y., Lumyong. S. (2005). Secondary metabolites from endophytic Streptomyces aureofaciens CMUAc130 and their antifungal activity. Microbiol, 151, 1691-1695, doi: 10.1099/mic.0.27758-0. 
[21] Velho-Pereira. S., Kamat. NM. (2011). Antimicrobial Screening of Actinobacteria using a Modified Cross-Streak Method. Indian J Pharm Sci, 73(2): 223-228, doi: 10.4103/0250474x.91566.

[22] Vineeta. S., Shafiul. H., Harshita. S., Jyoti. V., Kumari. V., Rajbir. S., Arshad. J., Tripathi. CKM. (2016). Isolation, Screening, and Identification of Novel Isolates of Actinomycetes from India for Antimicrobial Applications. Front Microbiol, 7, 1921, doi: 10.3389/fmicb.2016.01921.

[23] Zothanpuia., Passari. AK., Singh. BP. (2015). Molecular characterization of actinomycetes isolated from Tuichang river and their biosynthetic potential, Mizo Acad Sci, 15(3): 136-44. 